\title{
Ebelik Bölümü Öğrencilerinde Sağlıklı Yaşam Biçimi Davranışları İle Sınavların İlişkisinin İncelenmesi ${ }^{1}$
}

\author{
DOI: $10.26466 / o p u s .460834$
}

\section{Ayșegül Durmaz $^{*}$ - Çiğgem Gün ${ }^{* *}$}

${ }^{*}$ Dr. Öğr. Üyesi, Kütahya Sağlık Bilimleri Üniversitesi, Sağlık Bilimleri Fak. Kütahya/Türkiye E-Posta: aysegul.durmaz@ksbu.edu.tr ORCID: 0000-0002-3092-8841

${ }^{* *}$ Dr. Öğr. Üyesi, Mehmet Akif Ersoy Üniversitesi, Sağlık Bilimleri Fakültesi Burdur/Türkiye E-Posta: cgun@mehmetakif.edu.tr ORCID: $\underline{0000-0003-1951-563 \mathrm{X}}$

\begin{abstract}
Öz
Üniversite süreci bireylerin yaşamında önemli değişimlerin yaşandı̆̆g bir dönemdir. Gelecekteki sağllk durumlarınt, kişisel ve mesleki yaşam biçimlerini öğrenmek ve pekiştirmek için ideal bir dönemdir. Fakat üniversite sürecinde öğrencilerde sağlıksız davranışlara yönelim artmaktadır. Bu yönelimlerde öğrencilerin să̆lık davranışlarındaki değişimler, stres belirtileriyle ilişkili bulunmuştur. Özellikle sınav sürecinin, yoğun bir baskıya ve stres gelişimine neden olabileceği bildirilmiştir. Amaç: Ebelik bölümü öğrencilerinde sınav süreci ile sağllklı yaşam biçimi davranışlarının ilişkisini belirlemektir. Yöntem: Tanımlayıcı tasarlanan araştırmada tanıtıcı bilgi formu ve Să̆liklı Yaşam Biçimi Davranışları Ölçeği II kullanılmıştır. Çalışmaya 376 ebelik öğrencisi alınmıştır. Bulgular: Katılımcıların yaş ortalaması 20.33 \pm 1.69 , beden kitle indeksi (BKI) ortalaması $21.38 \pm 3.45$ ve kardeş sayısı ortalaması $2.56 \pm 1.79$ olarak saptanmıştır. \%35.1'inin yurtta kaldı̆̆g, \%57.2'sinin çekirdek aile yapısında olduğu ve \%45.5'inin gelirinin giderine eşit olduğu bulunmuştur. Sinavlardan önceki Sağlıklı Yaşam Biçimi Davranışları Ölçeği II toplam puan ortalaması 125.54 10.56 , sinavlardan sonraki să̆llklı yaşam biçimi davranışları ölçeği II toplam puan ortalaması $152.04 \pm 11.73$ olarak bulunmuştur. Sinav öncesi-sonrası ölçek toplam puan ortalaması ile ölçek alt boyutları (sağglk sorumluluğu, fiziksel aktivite, beslenme, manevi gelişim, kişiler arası ilişkiler, stres yönetimi) puan ortalamaları arasında anlamlı fark saptanmıştır ( $p<0.05)$. Sonuç olarak, katılımcılarda sınav sürecinin sağlıklı yaşam biçimi davranışlarını olumsuz etkilediği bulunmuştur.
\end{abstract}

Anahtar Kelimeler: Să̆glklı yaşam biçimi, Sinavlar, Öğrenci ebeler

\footnotetext{
${ }^{1}$ Bu çalışma III.Uluslararası Gençlik Araştırmaları Kongresinde sözlü bildiri olarak sunulmuş olup, özet metni ilgili kongre kitabında yayımlanmıștır.
}

OPUS (c) Uluslararası Toplum Araştırmaları Dergisi-International Journal of Society Researches ISSN:2528-9527 E-ISSN : 2528-9535

http://opusjournal.net 


\title{
Relationship Between Healthy Lifestyle Behaviors In Midwifery Students And The Exams
}

\begin{abstract}
University is a period when significant changes in the lives of individuals are experienced. It is an ideal period for the individuals to learn and enhance their future health conditions, personal and professional lifestyles. However, there is an increasing trend towards unhealthy behaviors in students during the university period. In these trends, changes in health behaviors of the students were related to stress symptoms. It has been reported that the exam process in particular can cause intense pressure and stress development. Objective: This study was designed to determine the relationship of the exam process with the healthy lifestyle behaviors in midwifery students. Method: In this descriptive study, a descriptive information form and Healthy Lifestyle Behavior Scale II was used. The study included 376 midwifery students. Results: The age average of the participants was $20.33 \pm 1.69$, the average of body mass index (BMI) was $21.38 \pm 3.45$, and the mean number of siblings was $2.56 \pm 1.79$. It was found that $35.1 \%$ of the students stayed in the dormitory, $57.2 \%$ had a nuclear family and $45.5 \%$ had equal income and expense. Total score average of Healthy Lifestyle Behavior Scale II was found as $125.54 \pm 10.56$ before the exams, whereas total score average of healthy lifestyle behavior scale II was found as $152.04 \pm 11.73$ after the exams. There was a significant difference between total score average of the pre-and post-exam scale and the sub-dimensions of the scale (health responsibility, physical activity, nutrition, spiritual development, interpersonal relations, stress management) $(p<0.05)$. Conclusion, It has been found that the exam process has adverse effects on the healthy lifestyle behaviors in the participants
\end{abstract}

Keywords: Healthy lifestyle behaviors, Exams, Midwifery students

OPUS @ C Uluslararası Toplum Araştırmaları Dergisi-International Journal of Society Researches ISSN:2528-9527 E-ISSN : 2528-9535

http://opusjournal.net 


\section{Giriş}

Sağlıklı yaşam biçimi davranışlarının erken yaşlarda uygulanmaya başlanması, sağlıklı ve üretken yetişkin nüfusa ulaşmaya yardımcı olabilir (Wald vd., 2014). Ayrıca sağlık, tüm insanların yaşamlarında önemli bir yere sahiptir. İnsanların yaşam kalitelerini iyileştirmek ve sağlıklarını korumak için sağlıklı yaşam biçimi davranışlarını geliştirmeleri gerekmektedir. Bunu görev olarak görürlerse, riskli faaliyetlerden ve davranışlardan kaçınacaklardır ki bu durum onların sağlığını korur ve geliştirir (Kurt, 2015). Bununla birlikte üniversite öğrencilerinin birçoğunun, sağlıklı yaşam biçimine uygun olmayan sağlık davranışları sergiledikleri bildirilmiştir (Wald vd., 2014). Hastalık Kontrol ve Önleme Merkezi (Center's of Disease Control and Prevention, CDC), genç nüfus arasında yaygın olarak görülen sağlık açısından riskli davranışları, kasıtsız yaralanmalar ve şiddete katkıda bulunan davranışlar, istenmeyen gebelik ve HIV "Human Immuno Deficiency Virus" enfeksiyonu dahil olmak üzere cinsel yolla bulaşan hastalıklarla ilgili cinsel davranışlar, alkol ve diğer uyuşturucu kullanımı, tütün kullanımı, sağlıksız diyet davranışları ve yetersiz fiziksel aktivite olarak belirlemiştir (CDC, 2018 ). Amerika Birleşik Devletleri'nde yapılan bir çalışmada, üniversite öğrencilerinin sadece \% 30 ile \% 50'sinin fiziksel olarak aktif olduğu ve \% 25'inin her gün en az beş porsiyon sebze ve meyve tükettiği bildirilmiştir. Ayrıca öğrencilerin düzenli uyku davranışlarının genellikle zayıf olduğu ve uyku yoksunluğu yaşadıkları saptanmıştır (Wald vd., 2014). İspanyol üniversite öğrencileri üzerinde yapılan benzer bir çalışmada da sağlıksız yaşam biçimi davranışlarının bulunduğu, bu durumun özellikle kız öğrencilerde daha fazla göze çarptı̆̆ bildirilmiştir. Öğrencilerin sadece \%27,4'ünün yeterince aktif olduğu, \% 14,9'unun yeme bozukluğundan rahatsız olduğu belirtilmiştir. Kız öğrencilerin erkek öğrencilerden daha sedanter yaşad1ğ1 gözlenmiştir. Aşırı alkol alımı kız öğrencilerde daha fazla saptanmıştır. Analiz edilen örneklemin üçte biri, yasadışı maddeler kullandığını itiraf etmiştir (Varela-Mato vd., 2012). Hacıhasanoğlu ve arkadaşlarının (2011) çalışmasında ise, öğrencilerin sınıf düzeyinin, ebeveynlerinin eğitim durumunun, öğrencilerin ve ailelerin gelir düzeylerinin, öğrencilerin ikamet yerinin ve sigara içme alışkanlıklarının sağlıklı yaşam biçimi davranışlarını etkilediğini saptanmıştır. Sınav, öğrencilerin akademik etkin- 
liğini ve başarı düzeyini belirlemede en çok kullanılan yöntemdir. Sınavlar eğitimin vazgeçilmez bir parçasıdır ve bu yöntem bazen öğrencilerde sıkıntılara sebeb olabilir (Karaaslan ve Çelebioğlu, 2018). Sınavlar nedeniyle öğrencilerin yaşadığı sıkıntılar arasında fiziksel ve sosyal faaliyetlere yetersiz katılım, yüksek düzeyde stres, anksiyete ve yorgunluk yer almaktadır. Sınav anksiyetesi artan öğrenci, başarısının test edilmesi söz konusu olduğunda varolan potansiyelinin tehlikeye girdiğini hissedebilir. Ayrıca bu öğrenciler sınavlarda olduğu gibi, gruplar arasında konuşma, yüksek sesle okuma gibi etkinliklerde de korkulu, sinirli, gergin ve heyecanlı hissederler. Yaşadıkları tüm bu olumsuzluklar odaklanmalarını engelleyebilir. Sınavlarda soruları okuma ve hatasız cevap verme, konuşma sırasında düşüncelerini organize edebilme, doğru kelimeleri seçebilme ve düzgün ifade edebilme gibi davranışlarda başarısız olabilirler (Kumandaş ve Kutlu, 2014). Yapılan çalışmalardan elde edilen sonuçlar sınav kaygısı ve akademik performans arasında ilişki olduğunu bildirmektedir (Hahn vd., 2017; Kavakci vd., 2014; Rezazadeh ve Tavakoli, 2009; Chapell vd., 2005). Ayrıca çalışmalarda bazı sağlık davranışlarının akademik performansla ilişkili olduğu bulunmuştur. Bunlar arasında sağlıklı beslenme davranışları, iyi kalitede beslenme, yeterli meyve ve sebze yeme, diyet yapmama, orta - güçlü düzeyde fiziksel aktivite, sağlık bilinci, alkol kullanmama veya sık olmayan alkol kullanımı, tütün kullanımı, başka uyuşturucu kullanımı, şiddet içermeyen davranış, yeterli uyku süresi, iyi kalitede uyku, erken uyumak-zamanında uyanma ve tutarlı prezervatif kullanımı gibi davranışlar yer almaktadır (Peltzer ve Pengpid, 2014; Cabrera vd., 2018; Ansari, Suominen, Draper, 2017; Faught vd., 2017; Correa-Burrows vd., 2016; Kurt, 2015). Ülkemizdeki bir çalışmada kız öğrencilerin beslenme ve sağlık sorumluluğunun erkek öğrencilerden ve erkek öğrencilerin fiziksel aktivite durumunun kız öğrencilerden daha yüksek olduğu belirlenmiştir (Tambağ, 2011). Benzer şekilde Özyazıcıoğlu ve arkadaşları (2011) hemşirelik bölümü öğrencilerinin sağlıklı yaşam biçimi davranışlarını orta düzeyde saptamıştır. Çalışmada öğrenci hemşireler sağlık sorumluluğundan en yüksek, fiziksel aktiviteden en düşük puanı almışlardır. Üniversite öğrencilerinin sağlıklı yaşam biçimi davranışları açısından araştırmalar incelendiğinde öğrencilerin sağlıklı yaşam biçimi davranışlarına yeterince önem vermedikleri gözlenmektedir. Topluma sağlıklı yaşam biçimi bilincinin kazandırılma- 
sında ve olumsuz sağlık davranışların yerine olumlu davranışların benimsetilmesinde ebeler önemli rol oynamaktadır. Bu nedenle ebeler öncelikle kendi sağlıklarını geliştirici davranışları sergilemeli ve hizmet verdiği bireylerin olumlu sağlık davranışı geliştirmesi için motive edici olmalıdır. Bu doğrultuda ebelik eğitimi gören öğrencilerin sağlıklı yaşam biçimi davranışlarını geliştirmesi beklenmektedir (Tambağ, 2011). Çalışmanın amaçları; (a) Ebelik öğrenimi gören öğrencilerin sağlıklı yaşam biçimi davranışlarını belirlemek, (b) sınav dönemlerinin sağlıklı yaşam biçimi davranışları üzerine etkisini incelemek ve (c) sağlıklı yaşam biçimi davranışlarının akademik performans üzerine etkisini ortaya çıkarmaktir.

\section{Yöntem}

\section{Araştırmanın Deseni}

Araştırma, tek gruplu, ön test-son test (yarı-deneysel) çalışmasıdır. Araştırmanın yapılabilmesi için kurum izni ve Dumlupınar Üniversitesi Rektörlüğü Etik Kurul'ndan onay alındı. Araştırma aşamasından sonuçlanmasına kadarki süreçte bilimsel etiğe ve akademik kurallara özenle riayet edildi. Araştırma güncel Helsinki Bildirgesi ve iyi klinik uygulamaları ilkelerine uygun olarak gerçekleştirildi. Araştırmanın verileri, kişisel verilerin gizliliğine riayet edilerek kaydedildi.

\section{Evren ve örneklem seçimi}

Araştırmanın evrenini 2017-2018 eğitim-öğretim yılında araştırmanın yapıldığ1 üniversitenin ebelik bölümünün 444 öğrencisi oluşturmuştur. Tüm öğrencilerin örnekleme dahil edilmesi planlanmıştır. Araştırma 376 öğrencinin (Katılım oranı \%84.69) katılımıyla tamamlanmıştır.

\section{Katılımcılar}

Dahil Edilme Kriterleri: Araştırmacılar tarafından bilgilendirildikten sonra kendi isteği ile araştırmaya katılmayı kabul eden, Sağlıklı Yaşam Biçimi Davranışları Ölçeği II'yi (SYBDÖ II) tam olarak dolduran, ön test 
ve son test olarak her iki uygulamaya da katılan ve tüm kayıtlı olduğu derslerin dönem sonu sınavlarına giren öğrenciler araştırma kapsamına alınmıştır.

\section{Uygulama}

Araştırmanın uygulaması Mayıs 2018 tarihinde yapıldı. Ön test ve tanıtıcı bilgi formu sinavlardan bir hafta önce, son test ise sinavlardan bir hafta sonra uygulandı (Öğrenciler ön testte kullandıkları rumuzları unutmamaları ve son testte de aynı rumuzu kullanmaları gerektiği konusunda bilgilendirildi). Uygulama öncesinde öğrencilere araştırmanın amaç ve yararları, araştırmadaki rolleri, veri toplama formlarına öğrenci kimliğini belirleyecek bilgilere yer verilmeyeceği konularında bilgi verildi. Öğrencilere araştırmaya katılımın gönüllük ilkesine dayandığı ve katılımın zorunlu olmadığı söylendi. Aaraştırmaya katılım için onay alındı. Öğrenciler araştırma verilerini oluşturan tüm formları kendileri doldurdu. Ön test ve tanitıcı bilgi formu sinıf ortamında toplandı. Öğrencilere cevap verebilmeleri için yeterli süre tanındı (yaklaşık 20 dakika). Son testi ise öğrenciler kendi ortamlarında (öğrenciler dönem sonu sinavlarından sonra memleketlerine döndükleri ve son test sinavlardan bir hafta sonra uygulandığı için) doldurarak, elden ulaştırd1 ya da e-mail yoluyla gönderdiler.

\section{Veri Toplama Araçları}

Veriler tanıtıc bilgi formu ve SYBDÖ II kullanılarak elde edilmiştir. Öğrencilerin akademik performanslarını belirlemek için Ağırlıklı Genel Not Ortalama (AGNO) puanları üniversitenin ilgili bölümünden alınmıştır. Tanıtıcı özellikler formu, öğrencilerin sosyodemografik özelliklerini içermektedir. Bu form; öğrencilerin sınıf, yaş, boy, kilo, doğum yeri, halen yaşadığı yer, kardeş sayısı, aile tipi, anne ve babanın öğrenim durumu, anne ve babanın çalışma durumu, gelir düzeyi, sigara, alkol kullanma durumu, sürekli kullandığı ilaç ve sağlığı algılamalarına yönelik bilgileri içeren toplamda 17 sorudan oluşmaktadır. Sağlıklı yaşam biçimi davranışları ölçeğinin ilk sürümü Walker tarafından 1987 yılında geliştirilmiştir. Ölçek 1996 yılında tekrar çalışılarak revize 
edilmiş ve Sağlıklı Yaşam Biçimi Davranışları Ölceği II olarak adlandırılmıştır. SYBD II ölçeğinin Türkçe uyarlaması Bahar, Z., Beşer, A., Gördes, N., Ersin, F. ve Kıssal, A. (2008) taraından yapılmıştır. Ölçek 52 madde ve altı faktörden oluşmaktadır. Bunlar; manevi gelişim, kişilerarası ilişkiler, beslenme, fiziksel aktivite, sağlık sorumluluğu ve stres yönetimidir. Ölçeğin güvenirlik katsayısı olan Cronbach Alpha değeri, toplam ölçek için 0.94 olup, altı alt faktörler için 0.79-0.87 arasında değişim göstermektedir. Alt ölçekler; Sağlık sorumluluğu, fiziksel aktivite, beslenme, manevi gelişim, kişilerarası ilişkiler ve stres yönetimidir. Ölçek, hiçbir zaman (1), düzenli olarak (4) olarak derecelendirilerek puanlanmıştır. Ölçeğin tamamı için en düşük puan 52, en yüksek puan $208^{\prime}$ dir. Toplam puan arttıkça, öğrencinin de daha fazla sağlıklı yaşam biçimi davranışına sahip olduğu kabul edilmektedir (Bahar vd., 2008). Araştırma için hesaplanan Cronbach Alpha değeri 0.71 olarak saptanmıştır.

\section{Verilerin değerlendirilmesi}

Veriler SPSS (Statistical Package for Social Sciences) 13 istatistik programı kullanılarak değerlendirilmiştir. Verilerin normal dağılıma uygunluğu Kolmogorov-Smirnov testi ile belirlenmiştir. Verilerin analizinde tanımlayıcı istatistikler (ortalama, standart sapma, sayı, yüzde), nonparametrik tesler (Kruskall-Wallis Testi ve Wilcoxon testi) ve parametrik tesler (Anova testi ve Bağımlı gruplarda T testi) kullanılmıştır. Testlerde $\mathrm{p}<0.05$ değeri anlamlı olarak kabul edilmiştir.

\section{Bulgular}

Öğrencilerin tanıtıcı özellikleri incelendiğinde; araştırmaya katılanların \%29.8'inin dördüncü sınıf öğrencisi olduğu, yaş ortalamalarının $20.33 \pm 1.69$, Beden Kitle İndeksi (BKİ) ortalamalarının $21.38 \pm 3.45$ ve kardeş sayısı ortalamalarının $2.56 \pm 1.79$ olduğu saptanmıştır. Öğrencilerin \%35.1'inin yurtta kaldığı, \%57.2'sinin çekirdek aile yapısında olduğu ve \%45.5'inin gelirinin giderine eşit olduğu bulunmuştur (Tablo 1). 
Tablo 1. Öğrencilerin Tanıtıcı Özelliklerine İlişkin Bulgular (N=376)

\begin{tabular}{lcccc}
\hline Özelikler & $\mathbf{n}$ & $\mathbf{\%}$ & Ortalama \pm SS & $\begin{array}{c}\text { Dağılım } \\
\text { Aralığ́ }\end{array}$ \\
\hline Yaş & & & $20.33 \pm 1.69$ & $18-36$ \\
Beden Kitle İndeksi (BKI) & & & $21.38 \pm 3.45$ & $15-35$ \\
Kardeş sayısı & & & $2.56 \pm 1.79$ & $0-11$ \\
Sınıf düzeyi & & & & \\
Birinci sınıf & 91 & 24.2 & & \\
İkinci sınıf & 88 & 23.4 & & \\
Üçüncü sınıf & 85 & 22.6 & & \\
Dördüncü sınıf & 112 & 29.8 & & \\
Kaldığ1 yer & & & & \\
Yurt & 132 & 35.1 & & \\
Ev arkadaşları ile ortak & 100 & 26.6 & & \\
Evde tek & 48 & 12.8 & & \\
Ailesi ile birlikte & 96 & 25.5 & & \\
Aile Yapısı & & & & \\
Çekirdek aile & 215 & 57.2 & & \\
Geniş aile & 119 & 31.6 & & \\
Parçalanmış aile & 42 & 11.2 & & \\
Gelir Düzeyi & & & & \\
Gelir giderden az & 120 & 31.9 & \\
Gelir gidere eşit & 175 & 46.5 & \\
Gelir giderden fazla & 81 & 21.5 & \\
\hline
\end{tabular}

Öğrencilerin annelerinin \%7.7'sinin okur-yazar olmadığ1, \%15.4'ünün üniversite ve üstü eğitim gördüğü ve \%43.1'inin lise mezunu olduğu belirlenmiştir. Babaların eğitim durumu incelendiğinde \%5.1'inin okuryazar olmadığ1, \%18.1'inin üniversite ve üstü eğitim gördüğü ve \%36.7'sinin lise mezunu oldu görülmüştür. Öğrencilerin annelerinin \%70.5'inin, babaların ise \%7.2' sinin çalışmadığı saptanmıştır (Tablo 2).

Araştırmaya dahil edilen öğrencilerin sınavlar öncesi SYBDÖ II toplam puan ortalaması $125.54 \pm 10.56$, sinavlar sonrası SYBDÖ II toplam puan ortalaması $152.04 \pm 11.73$ olarak bulunmuştur. Sınav öncesi-sonrası SYBDÖ II toplam puan ortalaması ile SYBDÖ II alt boyutları (sağlık sorumluluğu, fiziksel aktivite, beslenme, manevi gelişim, kişiler arası ilişkiler, stres yönetimi) puan ortalamaları arasında istatistiksel olarak fark saptanmıştır $(\mathrm{p}<0.05)$. 
Tablo 2. Öğrencilerin Ebeveynlerine Ait Özellikler $(N=376)$

\begin{tabular}{lcc}
\hline Özellikler & $\mathbf{n}$ & \% \\
\hline Annenin öğrenim durumu & 29 & 7.7 \\
Okur-yazar değil & 71 & 18.9 \\
İlkokul mezunu & 56 & 14.9 \\
Ortaokul mezunu & 162 & 43.1 \\
& 58 & 15.4 \\
Lise mezunu & & \\
Üniversite mezunu ve daha üstü & & \\
\hline Babanın öğrenim durumu & 22 & 5.9 \\
Okur-yazar değil & 79 & 21.0 \\
İlkokul mezunu & 69 & 18.4 \\
Ortaokul mezunu & 138 & 36.7 \\
& 68 & 18.1 \\
Lise mezunu & & \\
Üniversite mezunu ve daha üstü & & \\
\hline Annenin çalışma durumu & 111 & 29.5 \\
Çalş̧yor & 265 & 70.5 \\
Çalşmıyor & & \\
\hline Babanın çalışma durumu & 349 & 92.8 \\
Çalışyor & 27 & 7.2 \\
Çalşsmıyor & &
\end{tabular}

Sınavlar öncesine göre sınavlardan sonra öğrencilerin daha sağlıklı yaşam biçimi davranışları gösterdikleri belirlenmiştir. Alt boyut puan ortalamaları tablo 3' de verilmiştir (Tablo 3).

Araştırmada SYBDÖ II toplam puanı bağlamında hem sınav öncesi hem de sınav sonrası sağlıklı yaşam biçimi davranışları açısından BKI düşük öğrencilerin BKİ yüksek olan öğrencilere $(\mathrm{p}<0.05)$, kardeş sayısı az olan öğrencilerin kardeş sayısı çok olan öğrencilere $(p<0.05)$, geliri giderinden fazla olan öğrencilerin geliri giderinden az olan öğrencilere $(p<0.05)$, çekirdek ailede yaşayan öğrencilerin geniş ailede yaşayan öğrencilere $(\mathrm{p}<0.05)$ ve evde tek kalan öğrencilerin yurtta kalan öğrencilere $(p<0.05)$ göre daha sağlıklı yaşam biçimi davranışlarına sahip oldukları belirlenmiştir. 
Tablo 3. Öğrencilerin Sinavlardan Önce ve Sonra SYBDÖ II Alt Boyut - Toplam Puan Ortalamaları (N=376)

\begin{tabular}{|c|c|c|c|c|c|}
\hline \multirow[t]{2}{*}{ Özellikler } & \multirow[t]{2}{*}{ Min. } & \multirow[t]{2}{*}{ Max. } & \multirow[t]{2}{*}{ Ort $\pm S D$} & \multicolumn{2}{|c|}{$\begin{array}{c}\text { İstatistiksel Anlamlılık } \\
\text { Wilcoxon Testi }\end{array}$} \\
\hline & & & & $\mathbf{z}$ & $\mathbf{p}$ \\
\hline Sağlık sorumluluğu & 9 & 31 & $21.57 \pm 4.23$ & & \\
\hline Sınavlardan Önce & & & & -16.40 & 0.00 \\
\hline Sinavlardan Sonra & 12 & 36 & $26.50 \pm 3.58$ & & \\
\hline Fiziksel aktivite & 8 & 29 & $19.29 \pm 3.87$ & & \\
\hline Sinavlardan Önce & & & & -14.01 & 0.00 \\
\hline Sinavlardan Sonra & 10 & 36 & $23.67 \pm 4.42$ & & \\
\hline \multicolumn{6}{|l|}{ Beslenme } \\
\hline Sınavlardan Önce & 8 & 31 & $20.44 \pm 4.65$ & -16.23 & 0.00 \\
\hline Sinavlardan Sonra & 20 & 36 & $28.51 \pm 3.18$ & & \\
\hline \multicolumn{6}{|l|}{ Manevi gelişim } \\
\hline Sinavlardan Önce & 14 & 31 & $22.82 \pm 3.34$ & -3.00 & 0.00 \\
\hline Sinavlardan Sonra & 14 & 35 & $23.06 \pm 3.60$ & & \\
\hline \multicolumn{6}{|l|}{ Kişiler arası ilişki- } \\
\hline Sınavlardan Önce & & & & & \\
\hline Sinavlardan Sonra & 20 & 36 & $27.36 \pm 2.95$ & & \\
\hline \multicolumn{6}{|l|}{ Stres yönetimi } \\
\hline Sınavlardan Önce & 8 & 29 & $19.05 \pm 4.02$ & -16.03 & 0.00 \\
\hline Sinavlardan Sonra & 13 & 32 & $22.94 \pm 3.65$ & & \\
\hline \multicolumn{6}{|l|}{ SYBDÖ II Toplam } \\
\hline Sınavlardan Önce & 94 & 153 & $125.54 \pm 10.56$ & -16.81 & 0.00 \\
\hline Sinavlardan Sonra & 122 & 195 & $152.04 \pm 11.73$ & & \\
\hline
\end{tabular}

BKİ ve kardeş sayısı ile sağlıklı yaşam biçimi davranışları arasındaki ilişkinin istatistiksel açıdan anlamlı negatif bir ilişki olduğu saptandı (Tablo 4).

Öğrencilerin sınavlar sonrası AGNO 2.65 \pm 0.59 olarak belirlenmiştir. Sınavlar öncesi ve sonrası SYBDÖ II toplam puan ortalaması ve alt boyutlarının puan ortalamaları ile AGNO arasında istatistiksel olarak fark bulunmuştur $(\mathrm{p}<0.05)$. 
Tablo 4. Öğrencilerin Tanımlayıcı Özelliklerine Göre Sınavlardan Önce ve Sonra SYBDÖ II Toplam Puan Ortalamaları (N=376)

\begin{tabular}{|c|c|c|}
\hline Özellikler & $\begin{array}{c}\text { Sinavlardan Önce } \\
\text { Ort } \pm \text { SD }\end{array}$ & $\begin{array}{c}\text { Sinavlardan Sonra } \\
\text { Ort } \pm \text { SD }\end{array}$ \\
\hline $\begin{array}{l}\text { BKİ }(21.38 \pm 3.45) \\
\mathbf{W}^{*} \\
\mathrm{p}^{* *} \\
\mathbf{R}^{* * *} \\
\mathrm{p}^{* * * *}\end{array}$ & $\begin{array}{c}125.54 \pm 10.56 \\
45.89 \\
0.01 \\
-0.123 \\
0.00\end{array}$ & $\begin{array}{c}152.04 \pm 11.73 \\
36.53 \\
0.01 \\
-0.06 \\
0.00\end{array}$ \\
\hline $\begin{array}{l}\text { Kardeş Sayısı }(2.56 \pm 1.79) \\
\mathbf{W}^{*} \\
\mathbf{p} \\
\mathbf{R}^{* * *} \\
\mathbf{p}^{* * * *}\end{array}$ & $\begin{array}{c}125.54 \pm 10.56 \\
41.67 \\
0.00 \\
-0.06 \\
0.00 \\
\end{array}$ & $\begin{array}{c}152.04 \pm 11.73 \\
34.27 \\
0.00 \\
-0.03 \\
0.00 \\
\end{array}$ \\
\hline $\begin{array}{l}\text { Gelir Düzeyi } \\
\text { Gelir giderden az } \\
\text { Gelir gidere eşit } \\
\text { Gelir giderden fazla } \\
\text { W* }^{*} \\
\text { p }\end{array}$ & $\begin{array}{c}121.73 \pm 11.39 \\
127.18 \pm 10.22 \\
127.65 \pm 8.37 \\
18.55 \\
0.00 \\
\end{array}$ & $\begin{array}{c}148.60 \pm 10.86 \\
151.22 \pm 8.65 \\
158.90 \pm 15.48 \\
19.15 \\
0.00 \\
\end{array}$ \\
\hline $\begin{array}{l}\text { Aile Yapısı } \\
\text { Çekirdek aile } \\
\text { Geniş aile } \\
\text { Parçalanmış aile } \\
\mathbf{W}^{*} \\
\text { p }\end{array}$ & $\begin{array}{c}128.73 \pm 8.94 \\
122.30 \pm 10.83 \\
118.41 \pm 11.38 \\
38.21 \\
0.00 \\
\end{array}$ & $\begin{array}{c}153.54 \pm 11.61 \\
150.81 \pm 11.60 \\
147.86 \pm 11.53 \\
11.18 \\
0.01 \\
\end{array}$ \\
\hline $\begin{array}{l}\text { Kaldığı yer } \\
\text { Yurt } \\
\text { Ev arkadaşları } \\
\text { Evde tek } \\
\text { Ailesi ile birlikte } \\
\mathbf{W}^{*} \\
\mathbf{p}\end{array}$ & $\begin{array}{c}122.09 \pm 9.57 \\
125.41 \pm 9.38 \\
131.00 \pm 8.43 \\
127.69 \pm 12.28 \\
31.64 \\
0.00\end{array}$ & $\begin{array}{c}149.25 \pm 8.70 \\
149.01 \pm 7.19 \\
164.58 \pm 15.32 \\
152.76 \pm 12.96 \\
53.56 \\
0.00\end{array}$ \\
\hline
\end{tabular}

* Kruskal Wallis Testi, ${ }^{* *}$ Kruskal Wallis Testi $p$ değeri, ${ }^{* * *}$ Regresyon Testi, ${ }^{* * * *}$ Regresyon Testi $p$ değgeri

Sınavlar öncesinde ve sınavlar sonrasında diğer öğrencilere göre daha sağlıklı yaşam biçimi davranışları sergileyen öğrencilerin AGNO'nın daha yüksek olduğu saptanmıştır (Tablo 5). 
Tablo 5. Öğrencilerin Sinavlardan Önce ve Sonra SYBDÖ II Alt Boyut - Toplam Puan Ortalamalarının Ă̆ırlıklı Genel Not Ortalaması İle İlişkisi (N=376)

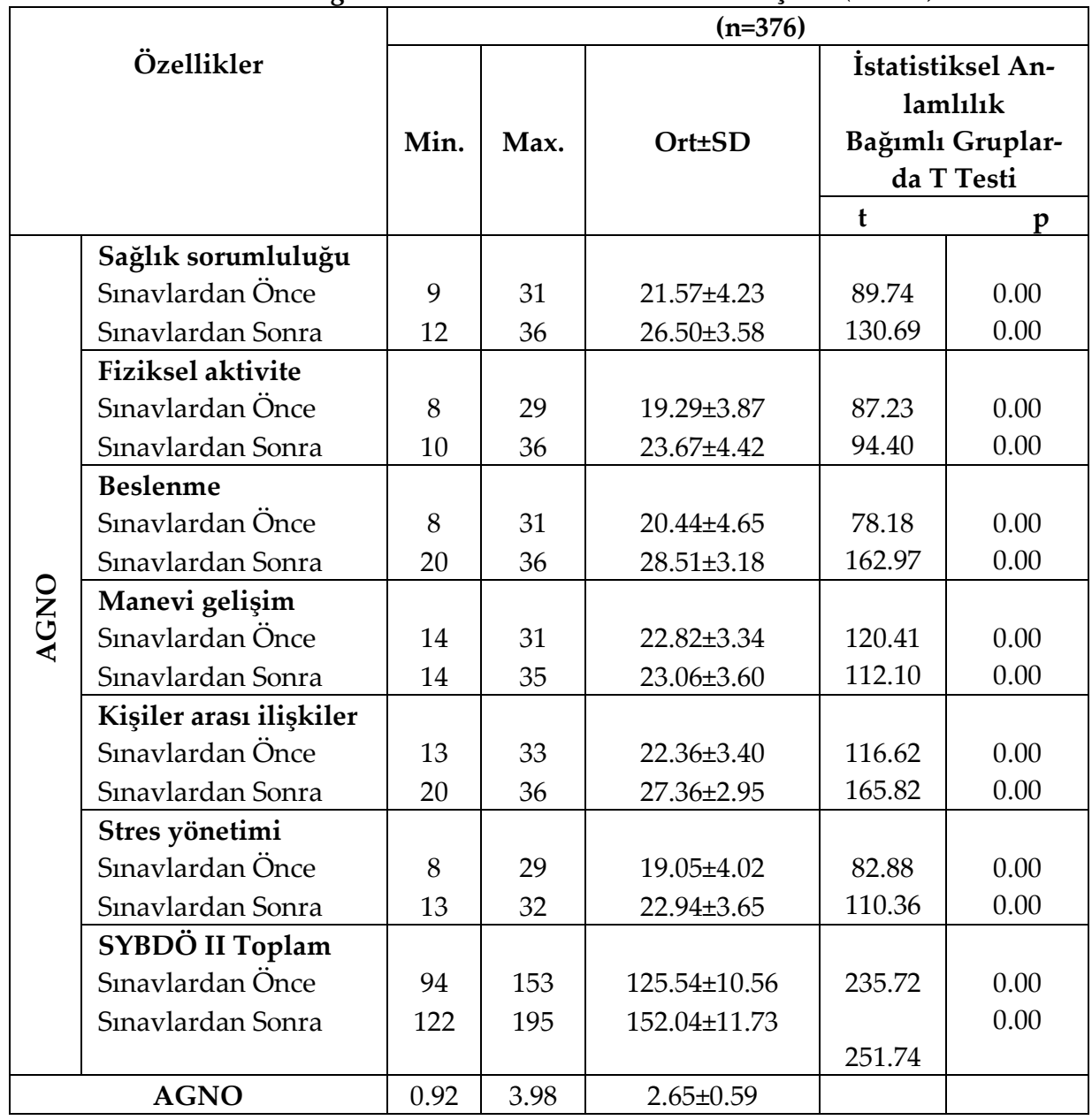

\section{Tartışma}

Sağlıklı yaşam tarzı, ciddi hastalıkları ya da erken ölüm riskini azaltan yaşam biçimidir (WHO, 1999). Sağlıklı bir yaşam tarzı geliştirmek için, Dünya Sağlık Örgütü (DSÖ) çok fazla meyve ve sebze yemeyi, yă̆, şeker ve tuz alımını azaltmayı ve egzersiz yapmayı önermektedir (WHO, 2018). Araştırmada ebelik bölümü öğrencilerinin sağlıklı yaşam biçimi 
davranışlarının sınav öncesi dönemde orta düzeyde, sınavlardan sonra ise ortalamanın üstünde olduğu saptanmıştır. Öğrencilerin sınavlardan sonra daha olumlu sağlıklı yaşam biçimi davranışları gösterdikleri belirlenmiştir. Sınavlardan sonra öğrencilerin sağlık sorumluluğu, fiziksel aktivite, beslenme, manevi gelişim, kişiler arası ilişkiler ve stres yönetimine daha fazla dikkat ettikleri gözlenmiştir. Özveren ve Yılmaz (2018), Mak ve arkadaşları (2018) Şen ve arkadaşları (2017), Sumen ve Oncel (2017), Murathan ve arkadaşları (2017), Kurt (2015), Wang, Xing, Wu (2013), Tambağ (2011), Hacıhasanoğlu ve arkadaşları (2011) tarafından yapılan çalışmalar incelendiğinde genel olarak üniversite öğrencilerinin sağlıklı yaşam biçimi davranışlarının orta düzeyde olduğu sonucuna ulaşılmaktadır. Bu çalışmaların sonuçları sınav öncesi dönemdeki sağlık11 yaşam biçimi davranışları bulgularımızla benzerdir. Aksoy ve Uçar (2014) hemşirelik öğrencileri üzerinde yaptıkları çalışmada, öğrencilerin sağlıklı yaşam biçimi davranışlarının ortalamanın üstünde olduğunu bildirmişlerdir. $\mathrm{Bu}$ bulgu araştırmadaki sınavlardan sonra elde edilen sağlıklı yaşam biçimi davranış puanları ile benzerdir. Araştırmaya dahil edilen öğrencilerin sınavlardan önce sağlıklı yaşam biçimi davranışlarının olumsuz etkilendiği ve sağlıklı yaşam biçimi davranış puanlarının sağlık bilimleri alanında öğrenim görmeyen öğrencilerle benzer olduğu söylenebilir. Bu bulgu öğrencilerin, sağlıklı yaşam biçimi davranışlarına yönelik öğrenimleri süresince kazandıkları bilgi ve becerileri kendi hayatlarına yeterli düzeyde yansıtamadıklarını göstermektedir. Araştırmada öğrencilerin BKİ azaldıkça daha olumlu sağlıklı yaşam biçimi davranışları sergiledikleri belirlenmiştir. Can ve arkadaşları (2008) yaptıkları çalışmada BKİ'nin hemşirelik öğrencilerinin sağlıklı yaşam biçimi davranışlarını etkilemediğini fakat BKİ azaldıkça diğer öğrencilerin sağlıklı yaşam biçimi davranışlarının olumlu etkilendiğini bildirmektedirler. Aceijas ve arkadaşları (2017), üniversite öğrencilerinin sağlıklı yaşamla ilişkili faktörlerini tanımladıkları çalışmada öğrencilerin BKİ'nin fiziksel aktivite ile ilişkili olduğunu belirtmektedir. Mak ve arkadaşları (2018) yaptıkları çalışmada hemşirelik öğrencilerinin sağlıklı yaşam biçimi davranışlarından fiziksel aktivitenin yaşam kalitesini geliştirici etkisi olduğunu bildirmektedir. Çalışmalar değerlendirildiğinde BKİ'nin sağlıklı yaşam biçimi davranışlarını etkilediği görülmektedir. 
Araştırmada öğrencilerin kardeş sayısı azaldıkça daha olumlu sağlıklı yaşam biçimi davranışlarına sahip oldukları bulunmuştur. Kardeş sayısının azalması, ailenin refah düzeyinin ve çocuk için ayrılan zamanın artmasına neden olacağından sağlıklı yaşam biçimi davranışlarını olumlu yönde etkileyebilir.

Araştırmaya dahil edilen öğrencilerin gelir düzeyi arttıkça daha olumlu sağlıklı yaşam biçimi davranışları gösterdikleri saptanmıştır. Sumen ve Oncel (2017) tarafından yapılan sistematik incelemede öğrencilerin gelir düzeyinin yüksek olmasının sağlıklı yaşam biçimi davranışlarını olumlu etkilediği belirtmektedirler. Aksoy ve Uçar (2014) ise çalışmasında öğrencilerin sosyo-ekonomik düzeyinin düşük olmasının sağlıklı yaşam biçimi davranışlarını olumsuz etkilediğini bildirmektedirler. Benzer şekilde Can ve arkadaşlarının (2008) çalışmasında gelir düzeyinin yükselmesiyle sağlıklı yaşam biçimi davranışlarının olumlu etkilendiği bulunmuştur. Sonuçlarımızla benzer bulgular durumun öğrencilerin yüksek gelir düzeyine sahip olmasıyla yaşam koşullarının iyileşmesi sonucu sağlıklı yaşam biçimi davranışlarının olumlu yönde etkilendiğini gösterebilir.

Çekirdek aile yapısında olan öğrencilerin daha olumlu sağliklı yaşam biçimi davranışlarına sahip olduğu saptanmıştır. Sumen ve Oncel (2017) yaptıkları sistematik incelemede, öğrencilerin çekirdek ailede yaşamasının sağlıklı yaşam biçimi davranışlarını olumlu etkilediğini bildirmektedirler. Çekirdek ailede yaşayan öğrencilerin kendilerine daha fazla zaman ayırabildikleri ve ailelerinden destek alabildikleri için sağlıklı yaşam biçimi davranışlarının olumlu yönde etkilendiği düşünülebilir.

Yurtta kalan öğrencilerin daha olumsuz sağlıklı yaşam biçimi davranışları gösterdikleri bulunmuştur. Benzer şeklide Aksoy ve Uçar (2014) çalışmasında öğrencilerin yurtta kalmasının sağlıklı yaşam biçimi davranışlarını olumsuz etkilediğini belirtmektedir. Can ve arkadaşları (2008) yaptıkları çalışmada hemşirelik öğrencilerinin sağlıklı yaşam biçimi davranışlarını yaşadığı yerin (yurt, ailesinin evi ya da diğer) etkilemediğini fakat diğer bölümlerde öğrenim gören öğrencilerin ailesiyle birlikte yaşamasının (yurt, arkadaşı ya da diğer) sağlıklı yaşam biçimi davranışlarını olumlu etkilediğini bildirmektedirler. Üniversite eğitimi boyunca ailesiyle kalan öğrencilerin kendilerine daha fazla zaman ayırabildikleri ve bazı temel gereksinimlerini karşılamada (beslenme, uyku, stres yöne- 
timi v.b.) ailelerinden destek alabildikleri için sağlıklı yaşam biçimi davranışlarının olumlu yönde etkilendiği düşünülmektedir.

Araştırmada öğrencilerin sınavlardan sonra sağlıklı yaşam biçimi davranışları ölçeği alt boyutları (sağlık sorumluluğu, fiziksel aktivite, beslenme, manevi gelişim, kişiler arası ilişkiler, stres yönetimi) açısından daha olumlu davranışlar gösterdikleri belirlenmiştir. Mak ve arkadaşlarının (2018) çalışmasında sağlık sorumluluğu, manevi gelişim, stres yönetimi ve fiziksel aktivitenin yaşam kalitesini geliştirici etkisi olduğu bildirilmektedir. Özveren ve Yılmaz (2018) ise bireylerin sağlıkla ilgili yaşam kalitesinin \% 60'ının yaşam biçimine bağlı olduğunu belirtmektedir. Bu doğrultuda sağlıklı yaşam biçimi davranışlarının sınav dönemlerinden olumsuz etkilendiği ve bu durumun yaşam kalitelerini de olumsuz etkileyebileceği düşünülebilir.

Öğrencilerden sinavlar öncesinde ve sınavlar sonrasında diğer öğrencilere göre daha sağlıklı yaşam biçimi davranışları gösterenlerin akademik performansının daha yüksek olduğu saptanmıştır. Burrows ve arkadaşlarının (2017) sistematik incelemesi sonucunda, uygun beslenme biçiminin akademik başarıyı arttırdığı bulunmuştur. Benzer şekilde Stea ve Torstveit (2014) yaptıkları geniş kapsamlı kesitsel çalışmada, düzenli kahvaltı alışkanlığının, akademik başarıyı artırdığını bildirmiştir. Wald ve arkadaşları (2014) yaptıkları çalışmada, orta düzeyde fiziksel aktivite yapan, meyve ve sebze tüketen öğrencilerde akademik başarının daha yüksek olduğunu vurgulamaktadır. Peltzer ve Pengpid (2014) üç kıtada (Afrika, Asya ve Amerika) yürüttükleri çalışmada, olumlu sağlık davranışlarının (lifli gıdalar tüketmek, yağ ve kolesterolü önlemek, yüksek düzeyde fiziksel aktivite yapmak, uyuşturucu kullanmamak ve alkollü araba kullanmamak) akademik performansı artırdığını belirtmektedir. Faught ve arkadaşları (2017) adolesanlar üzerinde yaptıkları çalışmada, sık sebze-meyve tüketilmesinin, düzenli fiziksel aktivitenin ve kahvaltıakşam yemeği yemenin, akademik performansı arttırdığını saptamıştır. Sağlıklı yaşam biçimi davranışlarının günlük hayatta uygulanmasıyla birlikte, akademik performansın artması özellikle üniversite öğrencilerinin başarı elde etmesi için göz önünde bulundurulması gereken bir durumdur. 


\section{Sinırlılıklar}

Son testin verileri mail aracılığıyla ya da öğrenci tarafından direk teslim edilerek toplandığı için ulaşım zorluğu yaşanmış; geri dönüşler için sürekli takip gerekmiş ve öngörülemeyen kayıplar yaşanmıştır.

\section{Sonuçlar}

Araştırmada ebelik öğrenimi gören üniversite öğrencilerinin sağlıklı yaşam biçimi davranışlarının sınav öncesi dönemde orta düzeyde, sınavlardan sonra ise ortalamanın üstünde olduğu görülmektedir. Yeterli düzeye ulaşmaması verilen eğitim ve becerinin sağlıklı yaşam biçimi davranışları geliştirilmesine yönelik nispeten etkin olsa da istenen düzeyde olamadığını, yeteri kadar fark yaratılamadığını düşündürmüştür. Öğrencilerin BKİ'nin azalması, kardeş sayısının azalması, çekirdek ailede yaşaması, gelir düzeyinin artması ve evde tek kalması sağlıklı yaşam biçimi davranışlarını olumlu etkilemektedir. Ayrıca çalışmada sağlıklı yaşam biçimi davranışlarıyla, akademik performansta aynı doğrultuda artmaktadır. Ebeler hizmet verdikleri toplumun, sağlı̆̆ının geliştirilmesinde, sağlıklı yaşam biçimi davranışlarının kazandırılmasında ve topluma benimsetilmesinde önemli sorumlulukları olan meslek mensuplarıdır. Bu bölümde okuyan, orta düzeyde sağlıklı yaşam biçimi davranışları sergileyen öğrencilerin, gelecekte hizmet vereceği bireylere rol modeli olacağı düşünüldügünde, öğrencilerin sağlıklı yaşam biçimi davranışlarının daha istendik düzeye ulaşması için ebelik eğitiminde gerekli önem verilmeli ve üzerinde durulmalıdır. 


\title{
EXTENDED ABSTRACT
}

\section{Relationship Between Healthy Lifestyle Behaviors In Midwifery Students And The Exams}

\author{
Ayşegül Durmaz /Çiğdem Gün \\ Kütahya Health Science University / Mehmet Akif Ersoy University
}

People need to develop healthy lifestyle behaviors to improve their quality of life and to preserve their health. When the literature is reviewed, it is reported that the most of the university students exhibit healthy lifestyle behaviors that are not suitable for the former healthy lifestyle. The less time when students are spent on social and physical activities, and the increased anxiety, stress and fatigue levels are the problems caused by exams. The results obtained from the studies indicate a relationship between the exam anxiety and the academic performance. Midwives play an important role in being gained the awareness of healthy lifestyle and adopted the positive healthy lifestyle behaviors instead of the negative in the Society.

Objectives of the study; (a) To determine the healthy lifestyle behaviors of midwifery students, (b) examine the impact of exam periods on healthy lifestyle behaviors and (c) to reveal the impact of healthy lifestyle behaviors on academic performance.

The research was carried out on a single group with pre test-post test (Semi-empirical) in May 2018. In order to carry out the research, approval of the institution and The Ethics Committee were obtained. The sample of the study consisted of 376 students. The pre-test and personal information forms were applied one week before the exams and the posttest was applied one week after the exams. The data were obtained by using the personal information form and HLSB II. In order to determine the academic performance of the students, the grade point average (GPA) scores were taken from the related department of the university. Descriptive statistics (mean, standard deviation, number, and percentage), nonparametric tests (Kruskal-Wallis Test and Wilcoxon test) and 
parametric tests (Anova test and $\mathrm{T}$ test in Dependent groups) were used in the analysis of the data.

It was determined that $29.8 \%$ of the students were fourth grade students, the mean age was $20.33 \pm 1.69$, and the mean body mass index (BMI) was $21.38 \pm 3.45$. It was found that $35.1 \%$ of the students stayed in dormitories, $57.2 \%$ of them were in the nuclear family structure and $45.5 \%$ of them had their expenses which were equal to their income. The mean total score of the HLSB II before the exams was $125.54 \pm 10.56$, and the mean total score after the exams was $152.04 \pm 11.73$. There was a significant difference $(\mathrm{p}<0.05)$ between the mean scores of the pre-test post-test scores and the mean scores of the scale sub-dimensions (health responsibility, physical activity, nutrition, spiritual development, interpersonal relations, stress management). It was determined that the students became more careful of their healthy lifestyle behaviors during the period between the test itself and post-test than during between pre-test and the test itself. In the research, as checking the total/average points of HLSB II, it was determined that students had healthier lifestyle behaviors; with lower BMI than with higher BMI $(\mathrm{p}<0.05)$, with less number of siblings than with a high number of siblings $(\mathrm{p}<0.05)$, with the compound fraction rate of income over expenses than simple fraction $(p<0.05)$, with living in the nuclear family than living in the extended family $(p<0.05)$, with living at home than in dormitories $(p<0.05)$. There was a statistically meaningful negative relationship in regard to healthy lifestyle behaviors between BMI and number of siblings. After the exams, the students' GPA was determined as $2.65 \pm 0.59$. The students, who performed healthier lifestyle behaviors compared to the rest, were confirmed to get higher GPA in before and after the exams.

A healthy lifestyle is a way of life that reduces the risk of serious illness or premature death (WHO, 1999). To develop a healthy lifestyle, the World Health Organization (WHO) recommends eating more fruits and vegetables, reducing fat, sugar and salt intake, and taking exercise (WHO, 2018). In the study, it was found that the healthy lifestyle behaviors of midwifery students were at the middle level before the examination and above the average after the exams. The increase in academic performance with the application of healthy lifestyle behaviors in daily life is worthy to consider for the academic success of university students. 
In the study, it is seen that the healthy lifestyle behaviors of the university students studying at midwifery are at the middle level before the exam and above the average after the exams. Although the education and skills given are relatively effective for developing healthy lifestyle behaviors, the awareness rising couldn't be reached at the desired level and the results in regards to the desired level is challenging. Midwives are the members of the profession who have important responsibilities in developing the health of the society they serve, bringing healthy lifestyle behaviors in the society and enuring it to the society. In midwifery department, it is necessary to focus on and give importance to midwifery education so that students' healthy lifestyle behaviors reach to a more desired level.

\section{Kaynakça/References}

Aceijas, C., Waldhäusl, S., Lambert, N., Cassar, S. ve Bello-Corassa, R. (2017). Determinants of health-related lifestyles among university students. Perspectives in public health, 137(4), 227-236.

Aksoy, T. ve Uçar, H. (2014). Hemşirelik öğrencilerinin sağlıklı yaşam biçimi davranışları. Hacettepe Üniversitesi Hemşirelik Fakültesi Dergisi, 1(2), 53-67.

Bahar, Z., Beşer, A., Gördes, N., Ersin, F. ve Kıssal, A. (2008). Sağlıklı yaşam biçimi davranışları ölçeği II'nin geçerlik ve güvenirlik çalışmas1. Cumhuriyet Üniversitesi Hemşirelik Yüksekokulu Dergisi, 12(1), 1-13.

Burrows, T. L., Whatnall, M. C., Patterson, A. J. ve Hutchesson, M. J. (2017). Associations between dietary intake and academic achievement in college students: a systematic review. In Healthcare, 5(4), 60.

Cabrera, J. C., Rodriguez, M. C., Karl, S. R. ve Chavez, C. (2018). In what ways do health behaviors impact academic performance, educational aspirations, and commitment to learning? Paper presented at the annual meeting of the American Educational Research Association, New York,2-24. https://conservancy.umn.edu/bitstream/handle/11299/195435/2018-HeathBehaviors-AERA.pdf?sequence=1\&isAllowed=y (Erişim Tarihi:20.08.2018). 
Can, G., Ozdilli, K., Erol, O., Unsar, S., Tulek, Z., Savaser, S., ... Durna, Z. (2008). Comparison of the health-promoting lifestyles of nursing and non-nursing students in Istanbul, Turkey. Nursing \& Health Sciences, 10(4), 273-280. https://doi.org/10.1111/j.1442-2018.2008.00405.x

CDC, (2018). Centers for Disease Control and Prevention. Youth Risk Behavior Surveillance System. https://www.cdc.gov/healthyyouth/data/yrbs/index.htm (Erişim Tarihi:20.08.2018).

Chapell, M. S., Blanding, Z. B., Silverstein, M. E., Takahashi, M., Newman, B., Gubi, A. ve McCann, N. (2005). Test anxiety and academic performance in undergraduate and graduate students. Journal of educational Psychology, 97(2), 268-274.

Correa-Burrows, P., Burrows, R., Blanco, E., Reyes, M. ve Gahagan, S. (2016). Nutritional quality of diet and academic performance in Chilean students. Bulletin of the World Health Organization, 94(3), 185. El Ansari, W., Suominen, S. ve Draper, S. (2017). Correlates of achieving the guidelines of four forms of physical activity, and the relationship between guidelines achievement and academic performance: undergraduate students in Finland. Central European journal of public health, 25(2), 87.

Faught, E. L., Gleddie, D., Storey, K. E., Davison, C. M. ve Veugelers, P. J. (2017). Healthy lifestyle behaviours are positively and independently associated with academic achievement: An analysis of selfreported data from a nationally representative sample of Canadian early adolescents. PloS one, 12(7), e0181938. https://journals.plos.org/plosone/article?id=10.1371/journal.pone.0181938 (Erişim Tarihi:20.08.2018).

Hacıhasanoğlu, R., Yıldırım, A., Karakurt, P. ve Sağlam, R. (2011). Healthy lifestyle behaviour in university students and influential factors in eastern Turkey. International Journal of Nursing Practice, 17(1), 43-51.

Hahn, H., Kropp, P., Kirschstein, T., Rücker, G. ve Müller-Hilke, B. (2017). Test anxiety in medical school is unrelated to academic performance but correlates with an effort/reward imbalance. PloS one, 12(2), e0171220. www.ncbi.nlm.nih.gov/pubmed/28182781(Erişim Tarihi: 20.08.2018). 
Karaaslan, M. ve Çelebioğlu, A. (2018). Lise öğrencilerinin sağlıklı yaşam biçimi davranışlarının belirlenmesi. Journal of Human Sciences, 15(2), 1355-1361.

Kavakci, O., Semiz, M., Kartal, A., Dikici, A. ve Kugu, N. (2014). Test anxiety prevalance and related variables in the students who are going to take the university entrance examination. The Journal of Psychiatry and Neurological Sciences, 27, 301-307.

Kumandaş, H. ve Kutlu, Ö. (2014). Yükseköğretime öğrenci seçmede ve yerleştirmede kullanılan sinavların oluşturduğu risk faktörlerinin okul başarısı üzerindeki etkileri. Türk Psikoloji Dergisi, 29(74), 15-31.

Kurt, A. S. (2015). The relationship between healthy lifestyle behaviors and health locus of control among nursing and midwifery students. American Journal of Nursing Research, 3(2), 36-40.

Mak, Y. W., Kao, A. H., Tam, L. W., Virginia, W. C., Don, T. H. ve Leung, D. Y. (2018). Health-promoting lifestyle and quality of life among Chinese nursing students. Primary health care research \& development, 1-8.

Murathan, F., Uğurlu, F. M., Murathan, T. ve Koç, M. (2017). Beden eğitimi ve spor yüksekokulu öğrencileri ile sağlık yüksekokulu öğrencilerinin sağlıklı yaşam biçimi davranışlarının karşılaştırılması (adıyaman üniversitesi örneği). Electronic Turkish Studies, 12(3), 493-504.

Özveren, H. ve Doğan Yılmaz, E. (2018). Hemşirelik öğrencilerinin sağlıklı yaşam biçimi davranışları ile egzersiz davranışlarının incelenmesi. Journal of Human Sciences, 15(3), 1505-1518.

Özyazıcıoğlu, N., Kılıç, M., Erdem, N., Yavuz, C. ve Afacan, S. (2011). Hemşirelik öğrencilerinin sağlıklı yaşam biçimi davranışlarının belirlenmesi. Uluslararasi İnsan Bilimleri Dergisi, 8(2), 277-332.

Peltzer, K. ve Pengpid, S. (2014). Health behaviour and self-reported academic performance among university students: an international study. Mediterranean Journal of Social Sciences, $5(27$ P2), 998.

Rezazadeh, M. ve Tavakoli, M. (2009). Investigating the Relationship among Test Anxiety, Gender, Academic Achievement and Years of Study: A Case of Iranian EFL University Students. English Language Teaching, 2(4), 68-74. 
Şen, M. A., Ceylan, A., Kurt, M. E., Palancı, Y. ve Adın, C. (2017). Sağlık Hizmetleri Meslek Yüksekokulu Öğrencilerinin Sağlıklı Yaşam Biçimi Davranışları ve Etkileyen Faktörler. Dicle Tip Dergisi, 44(1), 112.

Stea, T. H. ve Torstveit, M. K. (2014). Association of lifestyle habits and academic achievement in Norwegian adolescents: a cross-sectional study. BMC public health, 14(1), 829.

Sumen, A. ve Oncel, S. (2017). Factors that affect healthy lifestyle behaviors of high school students in Turkey: A systematic review. European Journal Of Therapeutics, 23(2), 74-82.

Tambağ, Y. D. D. H. (2011). Hatay sağlık yüksekokulu öğrencilerinin sağlıklı yaşam biçimi davranışlan ve etkileyen faktörler. Hacettepe Üniversitesi Hemşirelik Fakültesi Dergisi, 18(2), 47-58.

Varela-Mato, V., Cancela, J. M., Ayan, C., Martín, V., ve Molina, A. (2012). Lifestyle and health among Spanish university students: differences by gender and academic discipline. International journal of environmental research and public health, 9(8), 2728-2741.

Wald, A., Muennig, P. A., O'Connell, K. A. ve Garber, C. E. (2014). Associations between healthy lifestyle behaviors and academic performance in US undergraduates: a secondary analysis of the American College Health Association's National College Health Assessment II. American Journal of Health Promotion, 28(5), 298-305.

Wang, D., X.H. Xing. ve X.B. Wu. (2013). Healthy lifestyles of university students in China and influential factors. Scientific World Journal, 9: $1-10$.

WHO, (1999). World Health Organization. Regional Office for Europe. Healthy living : what is a healthy lifestyle?. Copenhagen : WHO Regional Office for Europe. http://www.who.int/iris/handle/10665/108180 (Erişim Tarihi:20.08.2018).

WHO, (2018). World Health Organization. A healthy lifestyle. http://www.euro.who.int/_data/assets/pdf_file/0006/257919/Factsheet-2014-Food-and-Nutrition-Eng.pdf?ua=1 (Erişim Tarih: 12. 08. 2018). 
Ebelik Bölümü Öğrencilerinde Sağlıklı Yaşam Biçimi Davranışları İle Sınavların İlişkisinin İncelenmesi

WHO, (2018). World Health Organization. Unhealthy diets are the leading factor affecting health and wellbeing in every European country Erişim: http://www.euro.who.int/en/health-topics/disease-prevention/nutrition/a-healthy-lifestyle (Erişim Tarih:12.08.2018).

\section{Kaynakça Bilgisi / Citation Information}

Durmaz, A. ve Gün, Ç. (2018). Ebelik bölümü öğrencilerinde sağlıklı yaşam biçimi davranışları ile sınavların ilişkisinin incelenmesi. OPUS-Uluslararası Toplum Araştırmaları Dergisi, 9(16), 296-318. DOI: 10.26466/opus. 460834 